\title{
Client confidentiality: Perspectives of students in a healthcare training programme
}

\author{
N Nortjé, ${ }^{1}$ DPhil; J de Jongh, ${ }^{2}$ PhD \\ ${ }^{1}$ Department of Psychology, University of the Free State, Bloemfontein, South Africa \\ ${ }^{2}$ Department of Occupational Therapy, University of the Western Cape, Cape Town, South Africa
}

Corresponding author: Nico Nortjé (nortjenico@gmail.com)

\begin{abstract}
Background. Confidentiality is an important ethical principle for all health professionals and also has a legal bearing on duty. One of the most difficult issues health professionals face in their daily fieldwork practice is a conflict between their professional duties, as illustrated in keeping a patient's medical information confidential, and having empathy with a family member's need to know. This moral dilemma is difficult for students to circumvent and therefore this paper presents healthcare students' perspectives of confidentiality.

Methods. We aimed to explore healthcare students' views and experiences of confidentiality as an ethical principle by adopting a qualitative explorative approach. Purposeful sampling was undertaken where specific individuals with specific experiences were identified. Data were collected by means of written responses from two open-ended questions and analysed thematically. Two themes emerged.

Conclusion. Confidentiality, as with other ethical principles, is an important obligation of a good client-therapist relationship as identified by students. However, the students' responses illustrate that it cannot be absolute, and cognisance must be taken as to when it is acceptable, and even desirable, to override confidentiality because of conflicting, greater duties.
\end{abstract}

S Afr J BL 2016;8(1):31-34. DOI:7196/SAJBL.460

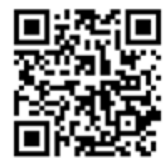

Confidentiality is an important and shared human value in Western bioethics and is included in international bioethical guidelines including the Helsinki declaration, Belmont report, guidelines of the Council for the International Organization of Medical Sciences (CIOMS), and many others. ${ }^{[1]}$ The obligation of the physician to preserve as confidential any information regarding his patient was first mentioned in the Hippocratic Oath:'What I may see or hear in the course of the treatment or even outside of the treatment in regard to the life of men, which on no account one must spread abroad, I will keep to myself, holding such things shameful to be spoken about.[2] However, the Hippocratic Oath has been criticised for enabling doctors to be selective in keeping medical confidentiality. The Geneva Declaration (1948) clearly stated that the physician shall preserve confidentiality on all he knows about the patient even after his death. ${ }^{[2]}$

Confidentiality is an ethical and a legal matter. In South Africa (SA), the origin of this legal position reflects a liberal individualistic dialogue as encapsulated in the Bill of Rights of the Constitution of the Republic of South Africa ${ }^{[3]}$ and the National Health Bill. ${ }^{[4]}$ The legal approach to confidentiality is based on an individualistic perception of patient autonomy in that patients are viewed as separate from others and free from social constraints when making informed choices, as long as they do not harm others. ${ }^{[5]}$ Benchmark judicial decisions have influenced medical confidentiality at large, such as the British example of the trial of the Duchess of Kingston in 1776. This trial reveals that the case that became the foundation of modern interpretations of medical confidentiality arose from little more than an attempt by a private surgeon, Caesar Hawkins, to secure his personal interests and status as a gentleman in eighteenth century high society. ${ }^{[6]}$

One of the most difficult issues medical health professionals face in their practice is a conflict between professional duties. Such a conflict may arise when they know that a patient's medical information has implications for family members but their professional duty to keep the information in confidence prevents them from disclosing it. ${ }^{[5]}$ However, research conducted in several countries, including England, Australia, Canada, and the USA demonstrates the importance of medical confidentiality to patients. Findings suggest that patients who believe that their confidentiality will be respected are more likely to seek treatment, discuss problems openly, and return for follow-up care. ${ }^{[7]}$

Absolute privacy, that is to say complete confidentiality of all information that the patient reveals to the healthcare provider, is neither possible nor desirable in the practice of medicine..$^{[8]}$ Effective, responsible medical treatment requires that we achieve a balance between disseminating patient information and keeping it private. Breaching confidentiality can be acceptable or required by medical authorities when failure to act could lead to physical harm either to the patient or to people in contact with that patient. ${ }^{[1]}$ This is illustrated by the Tarasoff case ${ }^{[9]}$ (where bodily harm was inflicted on Tatiana Tarasoff by a fellow student, who told a psychiatrist about it, which resulted in her death) and the case for progressive, infectious diseases, where the healthcare provider or researcher has a duty to protect the health of those who may be at risk. The ethics of public health has become more critical in an era of viral and multidrug-resistant bacterial epidemics ${ }^{[10]}$ such as the recent outbreak of Ebola. Although students understand what respecting confidentiality means, as laid down by the SA legal system, they often face ethical dilemmas as to when and to whom they may disclose information. Confidentiality, in the healthcare system of a developing country such as SA, can often not be given the same precepts as in Western countries. The investigation of the ethical principle of confidentiality is especially relevant to students in SA: 
- Firstly, within the primary healthcare (PHC) approach, most students work in diverse and predominantly poorer community settings. Subgroups within dominant cultures may respond differently to similar situations. ${ }^{[1]]}$ Therefore, students working in community settings have access to a client's family and personal life, as in a hospital setting.

- Secondly, the holistic and client-centred approach, used by students in their interventions, tends to involve not only the client as an individual but also the broader community which gives them access to sensitive information regarding the client as a holistic human being. ${ }^{[12]}$ This is particularly, but not solely, within the field of mental health. ${ }^{[13]}$ Therefore, we aimed to ascertain how healthcare students define confidentiality and in which cases, they argue, it may be breached.

\section{Sample and methodology}

A qualitative research approach was adopted as the aim was to explore healthcare students' views and experiences of confidentiality as an ethical principle. A non-probability sampling technique was used by inviting a cohort of 33 final-year healthcare students from a university in SA to participate in the study. Since this study is exploratory in nature, purposive sampling was employed where specific individuals with specific experiences were identified. ${ }^{[14]}$ The inclusion criteria included registration of the students in the Faculty of Community and Health Sciences and with the Health Professions Council of South Africa (HPCSA).

Data were collected by means of two open-ended questions to explore their views and experiences of confidentiality. The questions asked were:

- What is your understanding of the concept of confidentiality?

- When (if at all) is one allowed to breach confidentiality?

Participation was voluntary and all participants were assured that they could leave the study at any time without any adverse effect. The study protocol received ethics approval.

The reliability or consistency of the data analysis in qualitative research is an evolving process and can differ vastly from interpretation to interpretation. ${ }^{[14]}$ Of paramount importance to any qualitative study is the authenticity of the data which refers to the concept that a fair, honest, and balanced account of social life from the viewpoint of someone who lives it every day, ${ }^{[15]}$ has been given.

Thematic analysis is a method for identifying, analysing and reporting patterns (themes) within the data. 'It organises and describes data in detail.'[16] Thematic analysis involves searching for themes that emerge as being important to the description of the phenomenon. ${ }^{[17]}$ In this study data analysis was done as suggested by Terre Blanche, Durkheim and Kelly. ${ }^{[18]}$ The steps involved included:

- Familiarisation and immersion, i.e. a reading and re-reading of the text to get to know it

- Identifying codes that come directly from the data by breaking up the content into phrases, words or labels

- Collapsing the codes together into categories of the broader themes that were emerging through this process

- Comparing categories that belonged together or differed from one another so that data were no longer presented as linear columns but a collapse of various pieces of each into separate meaningful bundles or themes
- Interpreting themes and checking that interpretation with the participants.

\section{Results}

From the thematic analysis the following two most salient themes emerged:

- that students have a varied understanding of confidentiality but that most saw it as a relationship between healthcare provider and client

- that confidentiality may not be breached unless one is forced to by an organ of the state.

\section{Confidentiality as a relationship}

This theme highlights the participants' perceptions and understanding of confidentiality as an ethical principle. They described their understanding of confidentiality by using concepts like accountability, trust, safeguard, therapeutic relationship, agreement, respect, protect, being loyal, not sharing or revealing information and being faithful to your client. The participants tended to compare confidentiality closely with protecting the privacy of the individual or group to whom they provided a service. Most of the participants perceived confidentiality as an agreement between the health professional and the client. As participants quoted:

'It is an agreement to withhold any information regarding the client identity or any information they share with you.'

'In my opinion confidentiality is kept through the therapeutic relationship with my client and me.'

Some participants perceived confidentiality as a health professional's ethical and legal obligation to not disclose any information regarding their clients, without their consent. They experienced confidentiality in practice in order to build trust and strong interpersonal relationships. One participant highlighted:

'The aim is to create an environment of trust where the client is free to discuss anything knowing that his or her privacy, personal integrity and safety will be maintained within the process.'

Most participants experienced confidentiality as a sign of the respect that the health professional has for the client. According to the participants, they have a responsibility to respect, secure and protect the privacy of the client and the information. One participant quoted:

\section{'Confidentiality is the act of sacredly protecting your client.'}

Most of the participants believed that confidentiality could never be compromised and that it was necessary to promote a trusting and secure relationship with their clients within a safe environment. Even in situations where sharing of the client's information with those who have the appropriate authority to receive it, the quantity and content of the information provided should reflect a principle of 'need to know' basis only, as highlighted in the following quote:

'To me it all comes down to respecting as well as protecting my client's human right to privacy. 
All the participants experienced confidentiality as being loyal to their clients. For the participants to be loyal towards their clients did not only mean being faithful and trustworthy towards them, but maintaining a good relationship that is professional and therapeutic.

\section{Breaching confidentiality}

This theme captured the students' perceptions and views regarding the disclosure of client information and the reasons for breaching their confidentiality. All the students agreed that if any information about their clients had to be disclosed, they should be informed before commencing any interventions and that the client should give consent. From the findings it was evident that the only time that client confidentiality could be breached was when there was a threat to selfharm, harm to others or being a danger to society, and when the law requests information about a client. One participant said:

'Confidentiality is allowed to be broken when the client is a danger to him or herself or to others, when he or she is psychotic, when under the age of 16 , when information is needed for the court and when the client gives permission that information may be released.'

Some participants experience confidentiality as an oath that is taken by the health professional whereby it cannot be broken. Another quoted:

'As a professional we cannot divulge a client's information to other sources without their consent or knowledge.'

Most of the participants were of the opinion that when they are forced to disclose information, they will follow reasonable personal action when informing responsible authorities. All were in agreement that before disclosing client information the client should be informed so that trustworthiness present in the therapeutic relationship between the health professional and the client could be maintained. All these needs should be seen against the section of the National Health Act (61 of 2003) which explicitly emphasises that confidentiality may be broken:

- when patient's consent is ordered by a court of law or obligated by law (i.e. Children's Act 38 of 2005)

- when public health and/or safety is at risk.

\section{Discussion}

Confidentiality, as with other ethical principles, is an important obligation of a good patient-physician relationship. The philosophical foundation of this obligation is the acknowledgement of the dignity of patients as individuals and their universal right to control their own affairs. However, as with other ethical principles underlying that relationship, it cannot be absolute. Healthcare professionals should understand when it is acceptable, and even desirable, to override them because of conflicting, greater duties. ${ }^{[19]}$

The results suggest that students see confidentiality as a very important, almost non-negotiable, agreement between themselves and their patients/clients and that it must be 'sacredly' protected. A plausible explanation of why students would see it as an absolute rule could be that they see ethics as legalistic and rule-based to instruct rather than guide. Although the knowledge that confidentiality is important for the client-healthcare provider relationship and is a good point of departure, students should receive instruction that this is a principle and with experience the concept definition will develop into a non-absolute. The healthcare setting in SA necessitates this as many clients are being cared for by caregivers who are also an integral part of the team and need to be privy to some information. However, what to disclose is of the utmost importance and must be identified at the hand of the greater duty.

The literature is clear on when confidentiality may need to be breached ${ }^{[1,2,5,8]}$ - all efforts to do so must be with the client's consent. But if that cannot be achieved, the healthcare professional cannot escape their responsibilities to the public welfare, ${ }^{[20]}$ as is the present argument in the Ebola pandemic. Both legal precedents and quasi-legal standards such as codes of practice and professional guidance are usually justified, explicitly or implicitly, in terms of a utilitarian calculus; that disclosure in certain circumstances is justified because overall greater benefit will result than there would be from maintaining confidentiality. ${ }^{[2]}$ From the results it was interesting that some students held the opinion that confidentiality only becomes applicable if the client reaches a specific age (16 years) or is mentally stable (not psychotic). These misconceptions are a clear sign of seeing the duty of confidentiality as a legal requirement rather than one bestowed upon the deontological principle of autonomy of an individual, regardless of age or mental ability but rather as a right bestowed upon a person.

Enabling students to understand the impact of social norms on cultural diversity is important for healthcare educators and different cultural views of confidentiality should be included in training. SA is a pluralistic society and has an Anglo-Saxon cultural and philosophical tradition that excludes family from decision-making around the health (physical or mental) of an individual family member, as is illustrated by legal dictum such as the right to privacy as enshrined in section 12(2) of the Bill of Rights (Constitution of the Republic of South Africa, 1996).

\section{Implications for practice}

The undergraduate curriculum for training health professionals should not focus on ethical principles alone but should also introduce the concept of jurisprudence where students are taught the philosophy of law. This, together with developing critical reflection (Socratic dialogue), should encourage students to apply their knowledge and understanding of confidentiality and how this can change according to their duties to inform and protect. Furthermore, it is recommended that there should be increased efforts for students to engage in interdisciplinary education and practice. They should engage in joint reflections and dialogue around various practice issues, specifically related to confidentiality, as different members of an interdisciplinary team could hold different definitions.

Students should be exposed to SA common law and traditions where the elders of a clan often hold the decision-making power of those 'under their guidance'. This important contribution to the SA legal framework will encourage students not to become ethnocentric in their approach to healthcare but to be sensitive to broader cultural beliefs and traditions.

\section{References}

1. Alahmad G, Dierickx, K. What do Islamic Institutional Fatwas say about medical and research confidentiality and breach of confidentiality? Dev World Bioeth 2012;12(2):104-112. DOI:10.1111/j.1471-8847.2012.00329.x 
2. Papadodima SA, Spiliopoulou CA, Sakelliadis El. Medical confidentiality: Legal and ethical aspects in Greece. Bioethics 2008;22(7):397-405. DOI:10.1111/j.14678519.2008.00654.x

3. Republic of South Africa. The Constitution of the Republic of South Africa (108). Pretoria:Government Gazette, 1996. www.gov.za/documents/constitution/1996/ a108-96.pdf (accessed 20 August 2014).

4. Republic of South Africa. National Health Act (61). Pretoria: Government Gazette, 2003. www.gov.za/documents/download.php?f $=68039$ (accessed 20 August 2014).

5. Gilbar R. Medical confidentiality within the family:The doctor's duty reconsidered. Int J Law Policy Family 2004;18 (2):195-213. DOI:10.1093/lawfam/18.2.195

6. Ferguson $\mathrm{AH}$. The lasting legacy of a bigamous duchess: The benchmark precedent for medical confidentiality. Soc Hist Med 2006;19(1):37-53. PMID: 17153159

7. Jenkins G, Merz JF, Sankar P. A qualitative study of women's views on medical Confidentiality. J Med Ethics 2005;31(9):499-504. DOI:10.1136/jme.2004.010280

8. Brown B. Protecting the confidentiality of medical records in an interconnected environment. J Health Care Compli 2010;12(6):35-38.

9. Kyler-Hutchison P. Ethical reasoning and informed consent in occupational therapy. Am J Occup Ther 1988;42(5):283-287.

10. Balint J. Should confidentiality in medicine be absolute? Am J Bioeth 2006;6(2):19-20. PMID: 16500838

11. Lapine A,Wang-Cheng R, Goldstein M, Nooney A, Lamb G, Derse AR. When cultures clash: Physician, patient, and family wishes in truth disclosure for dying patients. J Pallitat Med 2001;4(4):474-480. PMID: 11798479
12. Sim J,Waterfield J.Validity, reliability and responsiveness in the assessment of pain. Physiother Theory Pract 1997;13(1):23-37. DOI:10.3109/09593989709036446

13. Sim J. Client confidentiality: Ethical issues in occupational therapy. Bri J Occupat Ther 1996;2:56-61. DOI:10.1177/030802269605900204

14. Nortjé N. Ethical tensions faced by dietetic students during fieldwork. S A J Clinical Nutri 20134;27(3):128-131.

15. Neuman WL. Basics of Social Research - Qualitative and Quantitative Approaches. 2nd ed. Boston: Pearson, 2007:108-139.

16. Braun V, Clarke V. Using thematic analysis in psychology. Qualitat Research Psychol 2006;3(2):77-101. DOI:10.1191/1478088706qp063oa

17. Fereday J, Muir-Cochrane E. Demonstrating rigor using thematic analysis: A hybrid approach of inductive and deductive coding and theme development. Inter J Qualitat Methods 2008;5(1):80-92.

18. Terreblanche M, Durrheim K, Kelly K. Firsts Steps in Qualitative Data Analysis. In: Terre Blanche M, Durrheim K, Painter D, eds. Research in Practice: Applied Methods in Social Sciences. 2nd ed. Cape Town: University of Cape Town Press, 2006:320-344.

19. Geiderman JM, Moskop JC, Derse AR. Privacy and confidentiality in emergency medicine: Obligations and challenges. Emerg Med Clin North Am 2006;24(3):633656. DOI:10.1016/j.emc.2006.05.005

20. Balint J. Should confidentiality in medicine be absolute? Am J Bioeth 2006;6(2):1920. DOI: $10.1080 / 15265160500506464$

21. Jones $C$. The utilitarian argument for medical confidentiality: A pilot study of patients' views. J Med Ethics 2003;29(6):348-352. DOI:10.1136/jme.29.6.348 